\title{
Comparative Evaluation of Tubal Patency by sterosalphingography and Laparoscopicchromopertubation
}

\author{
Dr. V. Geetha ${ }^{1}$, Dr. P. Thilagavathy ${ }^{2}$ \\ ${ }^{I}$ Department,Of Obstetrics And Gynaecology, Coimbatore Medical College And Hospital/The Tamil Nadu Dr. \\ MGR Medical University, India \\ ${ }^{2}$ Department Of Obstetrics And Gynaecology, Coimbatore Medical College And Hospital/The Tamil Nadu Dr. \\ MGR Medical University, India
}

\begin{abstract}
Ninety women, who attended the infertility clinic, were evaluated. Hysterosalpingography and laparoscopy with chromopertubation was done in all these 90 patients for assessment of tubal patency. The study analysed the efficacy of HSG versus laparoscopy and compared the correlation between the two methods. The results of the study showed that in diagnosing a patent tube the correlation between HSG and laparoscopy is $75 \%$ for patent tubes and $73 \%$ for blocked tubes. The sensitivity of HSG in diagnosing tubal pathology was $81 \%$ while specificity is $71 \%$. A high false positive rate of $29 \%$ in HSG was shown in this study. Keywords: Chromopertubation, Diagnostic Laparoscopy, Hysterosalpingography, Infertility, Tubal patency
\end{abstract}

\section{Introduction}

Infertility affects approximately $10-15 \%$ of reproductive age couples. Being labelled infertile is devastating to a couple. For the vast majority of patients, infertility is a totally unexpected blow to their future. They become desperate for help to achieve their goal of pregnancy and a child. Many times the problem of infertility has been blamed as the main reason for marital breakdown. The approximate prevalence of female factor of infertility is $40-55 \%$ of which tubal factors constitute $36-44 \%$. Evaluation of infertile patients has 4 important goals.

- To identify the cause of the infertility.

- To provide a basis for potentially successful treatment options

- To provide a realistic prognosis

- To offer emotional support

The purpose of this study is to critically evaluate the usefulness of the 2 important diagnostic modalities namely the HSG and laparoscopy in the diagnosis of infertility

\section{Aim}

- To compare the relative efficacy of Hysterosalphingography and Laparoscopy with chromopertubation in the diagnosis of tubal factors in infertile women.

- To assess the reliability of individual techniques in such infertile Women.

\section{Materials and methods}

Ninety women attending the Coimbatore Medical College Hospital's infertility clinic at Department of Obstetrics and Gynaecology between February 2015 and January 2016 who fit in the inclusion criteria were selected for the study. The patients were initially counselled along with their partner and a thorough history of both the partners was obtained followed by a general and pelvic examination of female partner.

Haemoglobin, urine analysis, Blood VDRL, Blood sugar were done. A Mantoux test was performed in female partner whenever necessary. Patients were carefully selected after excluding the contraindications for HSG and Laparoscopy.
3.1 Inclusion Criteria
a. Primary infertility
b. Age between 20 and $40 \mathrm{yrs}$
c. Duration of infertility at least $1 \mathrm{yr}$ in younger age $\mathrm{gp}$
d. Not suffering from other Medical illness
e. Normal seminal and other parameters in the partner 


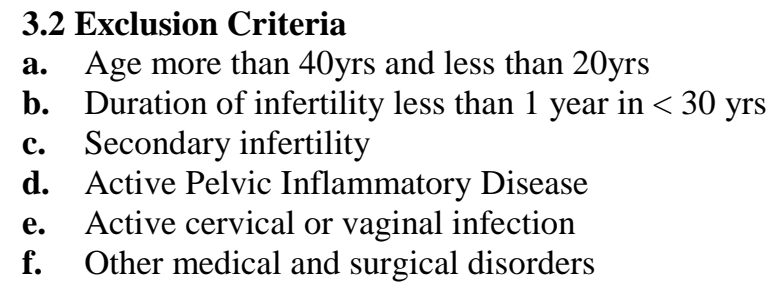

After initial evaluation of the patient and her partner HSG was performed by using Leech Wilkinson cannula with contrast 420 as contrast medium between $9^{\text {th }}$ and $11^{\text {th }}$ day of the cycle. No severe complications were met with barring few cases of low abdominal pain in the study.

Laparoscopy was done with double port in the secretory phase of the menstrual cycle under General anaesthesia. A thorough inspection of the uterus, tubes, ovaries and cul-de-sac was done. Findings were noted Chromopertubation was done by injecting the methylene dye and the nature of the spill visualized. The site of block, hydrosalpinx, and other pathology were noted.

At the end of the procedure an endometrial biopsy was taken for dating and to rule out Tuberculosis. Patient was allowed oral feeds after 6 hours and was discharged after 24 hours.

\section{Results and Observations}

All our patients were categorized according to the age distribution which shows that nearly $83 \%$ of the patients were within 30yrs age group. The analysis of duration of infertility shows that $75.6 \%$ of patients sought medical advice within 5yrs of Marriage. Patients with duration of infertility more than 5 years contributed to only $22.2 \%$. Only $2.2 \%$ patient in our study group had a duration of infertility for more than 10yrs.

In all the 90 patients, an initial HSG was performed to evaluate the tubal patency and uterine factors. In our study 42 patients had patent tubes and 48 had blocked tubes, the associated uterine pathology found was synechiae in 8 , Arcuate uterus in 2 and Bicornuate uterus in 1 and remaining 79 were normal.

In our series of 48 patients with blocked tubes in HSG, 13 patients had unilateral block and 35 patients had bilateral block, The site of tubal occlusion was most commonly found in midsegment of the tube in 24 cases, followed by Fimbrial block in 16 cases and proximal block in 8 cases

Diagnostic Laparoscopy with chromopertubation was performed in all 90 patients. The initial uterine and tubal findings during laparoscopy were Normal uterus in 82, Subserous Fibroid in 5, Arcuate uterus in 2 and Bicornuate uterus in 1. The Tubal finding were Normal tubes in 65, Peritubal adhesions in 22, Tubo ovarian mass in 2 and Hydrosalpinx in 1

On chromopertubation we found that 56 patients had patent tube, 34 patients had blocked tube, in which unilateral block was 12 , bilateral block was 22 , cornual block was 5 , mid segment block was 20 and fimbrial block was 9 .

The complete evaluation of tubal, peritoneal and uterine factors by laparoscopy focused upon the various factors responsible for infertility. Thus the tubal factors were suspected in 34 cases and uterine pathology contributed to 7 cases. The possible role of anovulation as confirmed by histopathological examination report in 26 cases. Endometriosis accounted for 6 cases where laparoscopy was instrumental.

\section{Discussion}

All the patients selected for the study were distributed according to their age. In our study $86.7 \%$ of patients were within 30 year of age.

According to Leon Spheroff [1], the causes for female subfertility are tubal and pelvic factors (40\%), ovarian factors (40\%), unexplained (10\%) and unusual (10\%). The commonly used tests for the diagnosis of tubal patency are HSG and laparoscopic chromopertubation. HSG has the additional advantage of detecting anomalies of uterine cavity

In our study with HSG it was found that 48 patients had tubal pathology, 11 patients had uterine pathology. Of those 11 patients with uterine pathology, 6 patients with synechiae also had tubal pathology. The remaining 5 had only uterine pathology and tubes were patent in them. Our study showed a high negative predictive value 0f $81 \%$. Opshal et al., 1993 studied the predictive value of HSG in tubal and peritoneal factors in 756 patients. HSG results were as normal, abnormal (bilateral distal tubal obstruction) or suspicious (all others). HSG was confirmed surgically in $96.6 \%$ of normals, $63.1 \%$ of suspicious and $95.7 \%$ of abnormal. Associated moderate-severe pelvic disease was found in $16.2 \%$ of normal, 53.9 of suspicious and $81.7 \%$ of abnormal. Abnormal HSGs are highly predictive of severe pelvic disease and does not require laparoscopy. Patients with suspicious HSG frequently have normal tubes but poor predictive value for tubal or associated pelvic disease so requiring confirmatory laparoscopy. Eventhough, normal HSG have a high negative predictive value it warrants diagnostic laparoscopy if nonsurgical treatment is unsuccessful[2]. 
When comparing the tubal patency in hysterosalpingography and laparoscopic chromopertubaion, it can be seen that more than half of the tubes were found to be patent in laparoscopic chromopertubation (62.2\%) where as it was only $47 \%$ on hysterosalpingography. Blocked tubes constituted $37.8 \%$ in laparoscopy and when compared to hysterosalpingography $(53 \%)$ the numbers were less. The false positives were high in HSG

The site of tubal blockade is mainly the mid segment as revealed by both diagnostic methods. Laparoscopy could demonstrate only half of those Fimbrial blocks which were diagnosed by HSG. Shah et al (2005) studied the accuracy of HSG to establish tubal patency, site of occlusion in 50 patients. HSG demonstrated $70 \%$ specificity for accurately diagnosing proximal tubal occlusion [3]

While analysing tubal patency more number of blocks were seen in HSG when compared to laparoscopy, the reasons might be

a. The fact that it was only a spasm that was mimicking a block in HSG.

b. Release of peritubal adhesion during laparoscopy facilitates the free flow of dye through fimbria.

c. A small fimbrial phimosis could easily be overcome by anaesthesia and forcible injection of dye.

Added advantage is that laparoscopy provides an overall picture of the pelvic structure, ovarian pathology along with tubal patency and architecture thus it helps in evaluating other causes of infertility. In our study we found 22 cases of peritubal adhesions, 10 cases of endometriosis, 5 cases of subserous Fibroid, 4 cases of tubo-ovarian mass, 2 cases of arcuate uterus, evidence suggestive of pelvic inflammatory disease was found in 2 cases and a case of bicornuate uterus. Laparoscopy was better than HSG in defining the tubal architecture even in those cases found to be having a patent tube in HSG. Donnez et al, 1982 (4) studied the incidence of pathological factors not revealed by HSG but disclosed by laparoscopy in 500 infertile women and demonstrated the agreement of tubal patency in $90 \%$ of cases. He also stated that HSG alone permits the diagnosis of peritubal adhesions in $68.8 \%$ of cases confirmed by laparoscopy[4]. Ngowa et al 2015 studied infertile patients and evaluated the causes of infertility by using both HSG and Laparoscopy. This study showed that HSG had 51\% sensitivity and $90 \%$ specificity in diagnosing proximal tubal occlusions. However, the study recorded a low sensitivity $(24.6 \%)$ and specificity $(45.4 \%)$ of HSG in diagnosing pelvic adhesions. Hence, this study emphasised that laparascopy should be performed in cases of abnormal HSG and even in cases of normal HSG in patients with unexplained infertility [5].

Hutchins 1977 et al assessed the tubal patency in HSG and diagnostic laparoscopy in 409 patients. Peritubal adhesion were detected by HSG in only 18 of the 54 cases where they were demonstrated by laparoscopy. Laparoscopy gave much useful information either at variance with or in addition to that yielded by HSG [6]

Lavy et al, 2004 assessed the diagnostic benefit of laparoscopy in infertile women with normal HSG in 86 patients. Laparsocopy may be omitted in women with normal HSG since it was not changed the original treatment indicated by HSG in $95 \%$ of patients. However laparoscopy should be recommended in cases with suspected bilateral occlusion on HSG since it altered the original treatment plan in $30 \%$ of patients from IVF to induction of ovulation with IUI [7].

The result of our study shows that HSG has a sensitivity of $80.9 \%$ in diagnosing tubal patency while the specificity is $70.8 \%$. Otubu et al (1990) had shown an accuracy of $91 \%$ and false positive rate of $9 \%$ in their study comparing HSG and laparoscopy in evaluation of tubal pathology [8].

Our study showed the false positives rate (28.16) to be high in HSG Hence which requires an early laparoscopy to confirm the diagnosis and for follow up action.

In our study the sensitivity of tubal pathology in infertile women by HSG shows a sensitivity of $80.9 \%$ and a specificity of $70.8 \%$ when HSG finding of a patent tube is seen, one can wait for 3 to 6 months with additional advantage of hoping for increase in fertility but it is not so in cases of blocked tubes, a high false positive rate of $28.16 \%$ is seen which implies that whenever a tube is found to be blocked, a laparoscopic chromopertubation has to be done to diagnose or refute the pathology.

Therefore it has been demonstrated from the study that HSG and laparoscopy with chromopertubation should be considered complementary to each other. This has also been highlighted in the study performed by Foroozanfard et al [9]. HSG and Laparoscopy are not alternative but are complementary methods in the examination of blocked tubes. Each have the merits and demerits of their own. Although laparoscopy was better than HSG as a predictor of future fertility, it should not be considered as the perfect test in the diagnosis of tubal pathology. For clinical Practice, laparoscopy can be delayed after a normal HSG for at least 6 months since the probability that laparoscopy will show tubal occlusion after a normal HSG in very low.

Mohammadbeigi and Tanhaeivash 2012 noted that HSG was 92\% sensitive and 70\% specific and hence HSG should be performed initially and the use of laparoscopy should be limited to patients whom extratubal pathologies are suspected such as endometriosis and peritubal adhesions[10]. 
Comparative Evaluation Of Tubal Patency By Hysterosalphingography And Laparoscopic

Sakar et al in 2008 studied 82 infertlie women and observed pathological findings in $45.1 \%$ by HSG and $65.85 \%$ by laparoscopy. HSG was $63 \%$ sensitive and $89.3 \%$ specific and the accuracy ratio was $72 \%$.and hence the above mentioned two methods are not alternative but complementary [11].

\section{Tables and Figures}

Table 1. Age distribution of infertility

\begin{tabular}{|l|l|l|}
\hline YEARS & Number & Percentage \\
\hline $20-25 \mathrm{yrs}$ & 53 & $58.9 \%$ \\
\hline $25-30 \mathrm{yrs}$ & 25 & $27.8 \%$ \\
\hline $30-35 \mathrm{yrs}$ & 11 & $12.2 \%$ \\
\hline$>35 \mathrm{yrs}$ & 1 & $1.1 \%$ \\
\hline
\end{tabular}

Table 2 Duration of infertility

\begin{tabular}{|l|l|l|}
\hline Years & Total Numbers & Percentage \\
\hline $1-5 \mathrm{yrs}$ & 68 & $75.6 \%$ \\
\hline $6-10$ & 20 & $22.2 \%$ \\
\hline$>10$ & 2 & $2.2 \%$ \\
\hline
\end{tabular}

Table 3 Finding in tubal patency by HSG

\begin{tabular}{|l|l|}
\hline Tubal patency & Number \\
\hline Patent tubes & 42 \\
\hline Blocked tubes & 48 \\
\hline
\end{tabular}

Table 4 Pathological causes of infertility diagnosed by HSG

\begin{tabular}{|l|l|}
\hline Pathology & Number \\
\hline Tubal & 48 \\
\hline Uterine & 11 \\
\hline Both & 6 \\
\hline
\end{tabular}

Table 5 Site of tubal block in HSG

\begin{tabular}{|l|l|}
\hline Site of block & Number \\
\hline Proximal tubal block & 8 \\
\hline Block at mid segment & 24 \\
\hline Fimbrial block & 16 \\
\hline
\end{tabular}

Table 6 Causes of infertility by laparoscopy

\begin{tabular}{|l|l|}
\hline Cause of infertility & Number \\
\hline Tubal factors & 34 \\
\hline Uterine factors & 7 \\
\hline Ovarian factors & 26 \\
\hline Endometriosis & 61 \\
\hline
\end{tabular}

Table 7 Patency of tubes as diagnosed by laparoscopic chromopertubation

\begin{tabular}{|l|l|l|}
\hline $\begin{array}{l}\text { Laparoscopic } \\
\text { chromopertubation }\end{array}$ & Number & Percentage \\
\hline Patent & 56 & $62.2 \%$ \\
\hline Blocked & 34 & $37.8 \%$ \\
\hline
\end{tabular}

Table 8 Comparison of tubal patency by hysterosalpingography and laparoscopic chromopertubation

\begin{tabular}{|l|l|l|l|l|}
\hline & \multicolumn{2}{|l|}{ Hysterosalpingography } & \multicolumn{2}{l|}{ Laparoscopic Chromopertubation } \\
\hline & Number & Percentage & Number & Percentage \\
\hline Patent tube & 42 & $47 \%$ & 56 & $62.2 \%$ \\
\hline Blocked tube & 48 & $53 \%$ & 34 & $37.8 \%$ \\
\hline
\end{tabular}

Table 9 Comparison between HSG and laparoscopic chromopertubation in the site of tubal blockade

\begin{tabular}{|l|l|l|l|}
\hline & Proximal & Midsegment & Fimbrial end \\
\hline HSG & 8 & 24 & 16 \\
\hline Laparoscopy & 5 & 20 & 9 \\
\hline
\end{tabular}

Table 10 correlation of HSG findings with laparoscopic chromopertubation

\begin{tabular}{|l|l|l|l|}
\hline & HSG & \multicolumn{2}{l|}{$\begin{array}{l}\text { Laparoscopic } \\
\text { Chromopertubation }\end{array}$} \\
\cline { 3 - 5 } & & Confirmation & Disagreement \\
\hline Patent tube & 42 & 42 & - \\
\hline
\end{tabular}




\begin{tabular}{|l|l|l|l|}
\hline Blocked tube & 48 & 34 & 14 \\
& & & \\
\hline \multicolumn{2}{|l|}{ Additional Pathology diagnosed during laparoscopy in those cases with patent tubes are } \\
Hydrosalpinx $\quad-1$ \\
Tubo ovarian mass -2 \\
Peritubal adhesion & -5 \\
Total & -8 & \\
\hline
\end{tabular}

Table 11 Showing comparative analysis of tubal block between HSG and laparoscopy

\begin{tabular}{|l|l|l|}
\hline \multirow{2}{*}{ HSG } & Tubal block as diagnosed by laparoscopy & \multicolumn{1}{|l|}{} \\
\cline { 2 - 3 } & Tubal block & Normal tubes \\
\hline Blocked Tubes & 34 & 14 \\
\hline Patent Tubes & 8 & 34 \\
\hline
\end{tabular}

Table 12 Results in our study

\begin{tabular}{|l|l|l|l|}
\hline & & Results & Estimate 95\% CI \\
\hline Sensitivity & & $81 \%$ & $66-91 \%$ \\
\hline Specificity & & $71 \%$ & $56-83 \%$ \\
\hline Positive predictive value & & $71 \%$ & $56-83 \%$ \\
\hline Negative predictive value & & $81 \%$ & $66-91 \%$ \\
\hline False positive & & $29 \%$ & $17-44 \%$ \\
\hline False negative & & $19 \%$ & $9-34 \%$ \\
\hline Correct classification & & $76 \%$ & $65-84 \%$ \\
\hline Kappa statistics & K-0.51 & Moderate agreement & \\
\hline
\end{tabular}
P-0.001

\section{Conclusion}

HSG being non invasive has a reasonably good sensitivity and specificity in diagnosing tubal pathology of infertile women. The high rate of false positive diagnosis of tubal pathology (29\%) by HSG, a follow up laparoscopy is warranted. Therefore laparoscopy and HSG are complementary to one another in diagnosing tubal and peritoneal factors and any infertility work up gives a more definite diagnosis when HSG findings was supplemented with laparoscopy.

By Laparoscopy, the fertility can be better assessed than HSG and accepted as the reference standard for determination of the accuracy of other diagnostic tools for tubal pathology

\section{References}

[1]. Marc A. Fritz and Leon Speroff, Clinical Gynaecologic Endocrinology and Infertility, $8^{\text {th }}$ edition, New Delhi, Lippincott Williams and Wilkins, 2011, 1137-90

[2]. Opshal MS, Mille B. Predictive value of hysterosalphingography for tubal and peritoneal factors. Journal of fertility steril 1993 Sep: 60(3): 444-8

[3]. Shah SM, Towobola OA, Mashihleho M. Diagnosis of fallopian tube patency, East Afr. Med. J. 2005, Sep : 82(9):457-62.

[4]. Donnez J, Hangerock S, Lecart C, Thomas K. Incidence ofpathological factors not revealed by hysterosalpingography but by laparoscopy. Eur. J. Obstet. Gynaecol. (1982);Sep:13(6):369-75

[5]. Ngowa JDK, Kasia JM, Georges NT, Nkongo V, Sone C, Fongang E Comparison of hysterosalpingograms with laparosocopy in the diagnostic of tubal factor of female infertility at theYaounde general Hospital, Cameroon Pan Afr Med . 2015; 22:264

[6]. Hutchins CJ (1977) Laparoscopy and hysterosalpingography in the assessment of tubal patency. Obstet Gynecol 49:325-327

[7]. Lavy Y, Lev-Sev-Sagie A, Holtzer H, Hurwitz A Laparoscopy be mandatory in infertile women with normal hysteroslaphingogram or suspected unilateral distal tubal pathology, Eur. J. Obstet Gynaecol 2004;May:114(1):64-8.

[8]. Otubu JA, Sagay As Hysterosalpingogram, Laparoscopy and Hysteroscopyin the assessment of the infertile Nigerian Female, East Afr Med J (1990) May; 67 (5): 370-2

[9]. Foroozanfard F, Sadat Z Diagnostic value of hysterosapingography and laparoscopy for tubal patency in infertile women Nurs Midwifery Stud. 2013 un 2(2):188-92

[10]. Mohammadbeigi R, Tanhaeivash R Comparison of hysterosalpingography and laparoscopy in infertile Iranian women with tubal factor. GinekolPol. 2012 Nov;83(11): 841-3

[11]. Sakar MN, Gul T. Atay AE, Celik Y Comparison of hysterosalpingography and laparoscopy in the evaluation of infertile women. Saoudi Med . 2008 Sep;29(9):1315-8 